\title{
Need for orthodontic treatment through the dental aesthetic index
}

\begin{abstract}
Summary
A descriptive, cross-sectional observational study was conducted with the objective of determining the need for orthodontic treatment using the Dental Aesthetic Index (DAI) in 9th grade students of the Alberto Fernández Montes de Oca Urban Basic Secondary School of the Dream Division in the period of September 2013-September 2014. The universe of study was 199 students between 13 and 14 years of age, of both sexes, with pure permanent dentition that had no posterior crossbite, posterior open bite, traumatic deep bite and without discrepancies of the midline. For the collection of the data the survey form of Buco-Dental Health designed by the WHO that includes the 10 components of the DAI was used. It was used as summary measures, absolute numbers and percentages. It was concluded that the need for priority and mandatory treatment predominated; the dental crowding was the most significant component of DAI.
\end{abstract}

Keywords: dental aesthetic, index, malocclusion, necessity, treatment, need, dental crowding, epidemiological purposes, orthodontic treatment, dental malocclusions, mixed dentition
Volume 2 Issue 6 - 2018

\author{
Ismilsi Fernández Pérez,' Josefa Navarro \\ Naples, ${ }^{2}$ Manuela Ricardo Reyes, ${ }^{3}$ Maira \\ Raquel Martínez Ramos, ${ }^{4}$ Mayelin Arza \\ Lahens ${ }^{5}$ \\ 'Specialist of I Degree in EGI,Teaching Provincial Stomatological \\ Clinic of Santiago de Cuba, Cuba \\ ${ }^{2}$ Specialist of II Degree in EGI, Master in Primary Health Care, \\ Medical University of Santiago de Cuba, Cuba \\ ${ }^{3}$ Specialist of II Degree in Orthodontics, Master in Community \\ Oral Health, Diploma in Higher Medical Education, Assistant \\ teacher, Cuba \\ ${ }^{4}$ Specialist of II Degree in Orthodontics, Master in Traditional \\ Natural Medicine, Medical University of Santiago de Cuba, Cuba \\ ${ }^{5}$ Second Degree Specialist in EGI. Master in Community Oral \\ Health, Medical University of Santiago de Cuba, Cuba
}

\author{
Correspondence: Josefa Navarro Naples, Specialist of II \\ Degree in EGI, Master in Primary Health Care, Assistant teacher, \\ Medical University of Santiago de Cuba, Cuba,
}

Email josefa.naverro@infomed.sld.cu

Received: July 26, 2018 | Published: November 19, 2018

\section{Introduction}

The position of the teeth within the jaws and the shape of the occlusion are determined by developmental processes that act on them and their associated structures during periods of postnatal formation, growth and modification. The smile is the gateway to human relationships, for this reason it is given so much importance to the care of the teeth especially its alignment in the dental arch. ${ }^{1}$ The Orthodontist plays a preponderant role in the promotion, prevention and correction of the occlusion anomalies from very early ages of life since they worsen as the age advances. ${ }^{2,3}$ Worldwide, several indexes are used to measure the need for orthodontic treatment, while they can be used to establish priorities in access to healthcare resources; to date none of these has been implemented in our environment. Among the most recent ones designed at the end of the 80 s and introduced in the 90 s, probably the most widely disseminated was the Dental Aesthetic Index (DAI), created for epidemiological purposes and adopted by the WHO for that purpose. ${ }^{4-6}$ It is suggested that malocclusion has epidemic characteristics of modern times. The scarce information published in Cuba about the epidemiology of dental malocclusions and in particular of the needs of orthodontic treatment, needs to identify the existent problematic regarding their possibilities of attention in the primary level, with the purpose that they can be treated from early ages through interceptive orthodontics, and the prevalence of dental malocclusions in late and permanent mixed dentition is reduced. ${ }^{4,5}$ The Dental Aesthetic Index (DAI) establishes a list of occlusal features or conditions in categories, ordered in a scale of degrees that allows to observe the severity of the malocclusions, which makes this condition reproducible and orientates according to the needs with respect to the Orthodontic treatment of the population. It includes two components: aesthetic and dental that uniting them mathematically allows obtaining a unique qualification where it combines the physical and aesthetic aspects of the occlusion. This Index was developed for permanent dentition, should be used in patients aged 12-18 years; but it can be adapted to the mixed dentition. ${ }^{5,6}$ The score resulting from this formula allows us to place the patient in one of the 4 categories or intervals DAI ranging from "normal occlusion" to "disabling malocclusion - priority treatment". Score 36 was chosen as the cut-off point to determine which malocclusions are disabling and which are not. ${ }^{5,6}$ Dental Aesthetic Index (DAI), is a rapid, universally accepted and applicable to populations of different countries and industrialized rural areas. It takes into account morphological, functional and aesthetic criteria. It is quantifiable; it does not require the use of radiographs, which generates advantages both in research and in the improvement of clinical practice standards. The use of the same criteria could favor the communication of the professionals with each other and with the patient, for its correct application and for it to have fidelity and reliability in the information obtained, it is necessary to take into account its limitations of use..$^{5-7}$ The Comprehensive General Dentist (EGI), is trained to perform actions of prevention and care of the oral health of patients, establish orthodontic measures to intercept dental malocclusions, preventing them from worsening and endangering the dental and functional balance, if not They are taken care of at the right time. ${ }^{3-8}$ By scarcity and need for these studies in the Provincial Teaching Dental Clinic was carried out or that, in order to determine the need for orthodontic treatment using Dental Aesthetic Index in 9 th grade school.

\section{Methods}

A descriptive study of transversal cut was performed in order to determine the need for orthodontic treatment through Esthetic 
Dentistry Index (DAI) in a universe of 199 schoolchildren between 13 and 14 years, of both sexes, 19th grade of Junior High School Urban Alberto Fernandez Montes de Oca Dream in the period September 2013 - September 2014 previous informed consent, good psychic and social status, with pure permanent dentition, that did not have the limitations of the index, of discrepancies of the midline, traumatic deep bite, posterior cross bite and posterior open bite limitations of the index. For the collection of the individual information, the Survey designed by the WHO that includes the 10 components of the DAI was used. ${ }^{6}$ and the data were obtained through the observation method, measurements, dental clinical examination and individual interviews. Among the variables we had: ${ }^{4}$ Normal occlusion or minimal malocclusion: No need for treatment or just minor treatment. Result of the DAI, less than or equal to 25. Defective malocclusion: require elective treatment. DAI result, between 26-30. Severe malocclusion: require convenient treatment. DAI result: between $31-35$. Very severe malocclusion: $r$ requires priority treatment. Result: Greater than or equal to 36 .

\section{Analysis of the results}

Table 1 shows the distribution of patients according to age and sex, where it can be seen that male gender represented $55.3 \%$ of all patients $\mathrm{L}$ Table 2 is a table relating to the patients in need of orthodontic treatment according to the DAI is observed that there was a predominance of need priority treatment with an ICD greater than or equal to 36 , the population studied with $29.6 \%$, followed by elective treatment with $26.1 \%$. In Table 3 , the need for orthodontic treatment according to sex is shown, obtaining a predominance in the male with very severe malocclusion of 31 schoolchildren what they require priority treatment. Table 4 it can be seen that there was a predominance of males in $76.4 \%$ with previous irregularity in the jaw of 3-4 $\mathrm{mm}$ and $60.3 \%$ of all examined. In Table 5 for the need for orthodontic treatment according to crowding and sex, there was a predominance of crowding of two segments in a $45.2 \%$, of the total of examinees, being the masculine sex the most affected with 50.0 $\%$. L Table 6 shows the need for treatment according overjet and sex was obtained that $50 \%$ of the 0.7 study population had an overjet 4-6 $\mathrm{mm}$, being the most affected with 58 female. $5 \%$. Table 7 shows the need for treatment according to the diastema in the midline and sex, it is found that the diastema of $0-2$ millimeters was the most significant; the male sex was the most affected with $84.5 \%$.

Table I Distribution of patients according to age and sex

\begin{tabular}{lllllll}
\hline Sex & 13 years & \multicolumn{3}{c}{ 14 years } & \multicolumn{3}{c}{ Total } \\
\cline { 2 - 6 } & No. & $\%$ & No. & $\%$ & No. & $\%$ \\
\hline Male & 1 & 100.0 & 109 & 55.1 & 110 & 55.3 \\
Female & 0 & - & 89 & 44.9 & 89 & 44.7 \\
Total & 1 & 100 & 198 & 100.0 & 199 & 100.0 \\
\hline
\end{tabular}

Source: Survey

\section{Discussion}

Optimal facial and dental esthetics are the goals of orthodontic treatment, but to achieve this result one must know the characteristics considered normal and pleasant in dental arches. ${ }^{9}$ The use of different indices has allowed us to correlate the main oral diseases in many population groups: caries, periodontal diseases and malocclusions, with several undoubtedly related risk factors. ${ }^{10}$ The results of the DAI in this study differ from Toledo et al. eleven regarding the distribution of the population by age and sex, $\mathrm{n}$ exposes a predominance of females $(52.8 \%)$ on $46.9 \%$ of male representatives. In a study similar to this one carried out in 12-year-old children in Chile ${ }^{1,2}$ Similar results were taken into both sexes, the component that measures the lost anterior teeth which had significant differences. The results of the study coincide with those found by Espinosa González, ${ }^{10}$ in a study conducted in Havana in schoolchildren of 6-18 years with a predominance of priority treatment need by $67 \%$. Silva-Esteves ${ }^{2}$ in his study found a $17.2 \%$ severe malocclusion below that obtained in this study of $29.6 \%$. Pined or $^{7}$ In his results according to the classification of severity of malocclusion of the DAI, he found that the defined malocclusion was the predominant one in the studied population with $32.8 \%$ corresponding to 58 models of study, which indicated a need for treatment and teaching. The anterior irregularity of the jaw in $60.3 \%$ of schoolchildren examined were given the disproportion between the size of the teeth and the bony bases and if one takes into account that the first permanent molars sprout first in the jaw than in the maxilla if there is late mesial shift there is a greater tendency to see the rotations. ${ }^{10}$

Table 2 Need for orthodontic treatment according to the ICD

\section{DAI Index Need for treatment No.\%}

25

Minor malocclusion (no treatment needed)

4221.1

$\div$ 26-30 Malocclusion defined (elective treatment)

5226.1

$\div 31-35$

Severe malocclusion (convenient treatment)

$\leq 36$

Very severe malocclusion (priority treatment)

5929.6

Total 199100.0

\section{*Source: Survey}

Table 3 Need for orthodontic treatment according to sex

\begin{tabular}{lllllll} 
Malocclusion & Male & \multicolumn{3}{c}{ Female } & \multicolumn{3}{c}{ Total } \\
& No. & \%* & No. & \%** & No. & \%*** \\
\hline $\begin{array}{l}\text { Minor } \\
\text { malocclusion }\end{array}$ & twenty & 18.2 & 22 & 24.7 & 42 & 21.1 \\
$\begin{array}{l}\text { Malocclusion } \\
\text { defined }\end{array}$ & 30 & 27.3 & 22 & 24.7 & 52 & 26.2 \\
$\begin{array}{l}\text { Severe } \\
\text { malocclusion }\end{array}$ & 29 & 26.3 & 17 & 19.1 & 46 & 23.1 \\
$\begin{array}{l}\text { Very severe } \\
\text { malocclusion }\end{array}$ & 31 & 28.2 & 28 & 31.5 & 59 & 29.6 \\
$\begin{array}{l}\text { Total } \\
\text { Mot. }\end{array}$ & $110 *$ & 100.0 & $89 * *$ & 100.0 & $19 * * *$ & 100.0 \\
\hline
\end{tabular}

Table 4 Need for orthodontic treatment according to sex and anterior irregularity in the jaw

\begin{tabular}{lllllll}
\hline $\begin{array}{l}\text { Irregularity } \\
\text { (in } \mathbf{~ m m} \text { ) }\end{array}$ & Male & \multicolumn{3}{c}{ Female } & \multicolumn{3}{c}{ Total } \\
\hline & No. & $\%$ & No. & $\%$ & No. & $\%$ \\
\hline 2-Jan & 26 & 23.6 & 53 & 59.6 & 79 & 39.7 \\
$4-$ Mar & 84 & 76.4 & 36 & 40.4 & 120 & 60.3 \\
Total & 110 & 100.0 & 89 & 100.0 & 199 & 100.0 \\
\hline
\end{tabular}


Table 5 Need for orthodontic treatment according to crowding in the incisal segments and sex

\begin{tabular}{lllllll}
\hline Crowding & Male & \multicolumn{3}{c}{ Female } & \multicolumn{3}{c}{ Total } \\
\hline & No. & $\%$ & No. & $\%$ & No. & $\%$ \\
\hline $\begin{array}{l}\text { No crowded } \\
\text { segment }\end{array}$ & 17 & 15.5 & 18 & 20.2 & 35 & 17.6 \\
$\begin{array}{l}\text { A crowded } \\
\text { segment }\end{array}$ & 38 & 34.5 & 36 & 40.5 & 74 & 37.2 \\
$\begin{array}{l}\text { two crowded } \\
\text { segments }\end{array}$ & 55 & 50.0 & 35 & 39.3 & 90 & 45.2 \\
Total & 110 & 100.0 & 89 & 100.0 & 199 & 100.0 \\
\hline
\end{tabular}

Table 6 Need for orthodontic treatment according to overjet and sex

\begin{tabular}{lllllll}
\hline $\begin{array}{c}\text { Overjet } \\
\text { (in } \mathbf{m m} \text { ) }\end{array}$ & Male & & Female & \multicolumn{3}{c}{ Total } \\
\hline \multirow{2}{*}{ to 3} & No. & $\%$ & No. & $\%$ & No. & $\%$ \\
4 to 6 & 49 & 26.4 & 22 & 24.7 & 51 & 25.6 \\
7 to 9 & eleven & 10.0 & 5 & 5.6 & 16 & 8.1 \\
10 a II & $\begin{array}{l}\text { twenty- } \\
\text { one }\end{array}$ & 19.1 & 10 & 11.2 & 31 & 15.6 \\
Total & 110 & 100.0 & 89 & 100.0 & 199 & 100.0
\end{tabular}

Table 7 Need for orthodontic treatment according to Diastema in the midline and sex

\begin{tabular}{llllllll}
\hline $\begin{array}{l}\text { Diastema in } \\
\text { the } \text { middle line } \\
\text { (in } \mathbf{m m} \text { ) }\end{array}$ & Male & & Female & & Total \\
\hline & No. & $\%$ & No. & $\%$ & No. & $\%$ \\
\hline 0 to 2 & 93 & 84.5 & 69 & 77.5 & 162 & 81.4 \\
3 to 4 & 17 & 15.4 & twenty & 22.4 & 37 & 18.5 \\
Total & 110 & 100.0 & 89 & 100.0 & 199 & 100.0 \\
\hline
\end{tabular}

The need for orthodontic treatment due to crowding in two segments means that individuals are not satisfied with their dental appearance. The predominance of crowding as a deficient occlusal feature can be explained according to Herpin's postulates, raised in his theory of the phylogenetic evolution of the human masticatory apparatus, based on the degeneration, so to speak, of the different elements that make it up, the decrease of the parts of the masticatory system has affected more the muscles and bones and less the teeth, which have reduced their size but not the number. ${ }^{9}$ Cartes $^{1-3}$ in his study found very severe or disabling malocclusion in $21.7 \%$, men showed $15.4 \%$ compared to women with $28.1 \%$; the most frequent alterations were the crowding of the previous sector with $86 \%$. An optimal smile is characterized by a superior lip that reaches the gingival margins, with an upward or straight curvature between the filtrum and the commissures; a superior incisal line coinciding with the edge of the lower lip; minimal or absent negative spaces; commissural line and frontal occlusal plane parallel to the pupillary line; and harmoniously integrated gingival and dental components. ${ }^{1-4}$ In the study and 1 overjet with 50,7 affected 4 to $6 \mathrm{~mm}$, more in women than in men can be given by the presence of any risk factors such as cigarette mouth breathing, tongue dysfunction and digital suction among other causes. The indication of early treatment for malocclusions once evaluated highlights the importance of assessing individuals with a wide age range in minor
19 years. ${ }^{1-5} \mathrm{E} 1$ midline diastema behaved majority 0 to $2 \mathrm{~mm}$ similar in both sexes, as previously stated, control of risk factors must be increased from an early age by the prevention and interception of malocclusions program.

E 1 midline diastema is caused by: Defective fusion premaxilar midline, low insertion of the upper lip frenum spacing as part of normal development, oligodontia lateral incisors, supernumerary teeth midline, microdontia and combinations ; its treatment is to eliminate the cause that produces it in a timely manner. The diastemas in the previous sector represent an aesthetic problem that can negatively influence the individual. ${ }^{1-5}$ Authors ${ }^{16,17}$ raise the aesthetic problem stands out as more frequent and more easily identifiable by the patient and his partner. An unfavorable dental aesthetic represents a significantly high risk that an individual will develop a disadvantage in relation to society, as a limitation in communication and social interaction, which will negatively influence the quality of life. The General Comprehensive Stomatologist as established by the program of the child less than 19 years should perform prevention and timely interception of diseases that increase their severity with age, which would avoid the results obtained in the study.

\section{Conclusion}

It is concluded that with the use of ICD in the study population, the need for priority or mandatory treatment turned out to be the most prevalent, followed by elective treatment and dental crowding, the most significant component of the ICD.

\section{Acknowledgements}

None.

\section{Conflict of interest}

The author declares there is no conflict of interest.

\section{References}

1. Sadi Guillermo, Alva Rimac, Hilarion Esdras. Prevalence, severity and need for orthodontic treatment of malocclusions according to the Dental Aesthetic Index in schoolchildren between 12 and 16 years of age, in the public educational institutions of the Ambo - Huanuco - Peru district, Thesis to obtain the title of dental surgeon November 2010. Faculty of Medical Sciences. 2010;20:106-138.

2. Pantaleào dos Santos MR, Isper Garbin A, Saliba Garbin CA, et al. Study of the occlusion characteristics of 12-year-old children from the municipality of Cáceres, Mato Grosso, Brazil. Acta Odontológica Venezolana. 2010;48(4).

3. Silva-Esteves Raffo F, Rivera N, Shirley. Various forms of early treatment of Pseudo Class III malocclusion. Report of cases Pediatric Dent. 2010;9(1):95-105.

4. Alemán Estévez MG, Martínez Brito I, Pérez Lauzurique A. Need for orthodontic treatment in schoolchildren. Application of the DAI. Rev Méd Electron. 2011;33(4).

5. Avilés Beltellón M, Huitzil Muñoz E, Fernández M. Orthodontic treatment need index (IOTN). Oral. 2011;12(39):782-785.

6. Pérez Aguilar V, García Reyes G, Cárdenas León A. Dental Aesthetic Index (DAI) and need for orthodontic treatment is school. Oral. 2009;29(9):472-75.

7. Pinedo Hernández Sarahi, Ayala Rojas Brenda, Vierna Quijano José María. Severity of malocclusions and the need for orthodontic treatment with the Oral Dental Aesthetic Index (DAI) 2012. Latin American 
Biomedical Journals. 2012;13(42):884-887

8. Fernández Ramírez L, Herrera López IB, Pellerano Sánchez TT. The family and oral health in: González Naya G, Montero del Castillo. General Comprehensive Stomatology, editorial medical sciences, Havana 2013. p. 41-50.

9. Rodríguez Soto A, Pérez Cordero Y, Fernández Collazo ME, et al Dentoalveolar trauma related to malocclusions in children under 15 years of age. Rev Cuban Stomatol. 2011;48(3):7.

10. Espinosa González Leticia. Behavior of oral diseases and treatment needs in a Vedado medical office. Rev Cubana Estomatol. 2004;41(3).

11. Toledo Reyes L, Machado Martínez M, Martínez Herrada Y, et al. Malocclusions for the dental aesthetic index (DAI) in the population under 19 years of age. Rev Cubana Estomatol. 2004;41(3).

12. Pérez María Antonieta, Neira Álvaro, Alfaro Javier. Need for orthodontic treatment according to the dental aesthetics index in adolescents of 12 years, Chile. Rev Fac Odontol Univ Antioq. 2012;26(1):33-43.
13. Cartas Velaquez Ricardo, Araya Eric, Valdés Carolina. Malocclusions and their Psychosocial Impact on Students of an Intercultural Lyceum. Int J Odontostomat. 2010;4(1):65-70.

14. Casas A, Bayona G. Aesthetics in orthodontics. Rev Estomat. $2010 ; 18(2): 33-38$

15. Kegler Eugenio, Jorge Arce, Miguel Samaniego. Aesthetic remodeling of the smile with composite resin: conservative alternative in young patients with multiple diastemas. Venezuela. 2012;50(3).

16. Aliaga del Castillo Aron, Mattos Vela MA, Aliaga del Castillo Rosalind. Malocclusions in children and adolescents from hamlets and native communities of the Amazon region of Ucayali, Peru. Rev perú med exp public health. 2011;28(1):87-91.

17. Avilés Beltellón M, Huitzil Muñoz E, Fernández M. Orthodontic treatment need index (IOTN). Oral. 2011;12 (39):782-785. 